\title{
La asamblea de deliberación: estrategia para la edificación de acuerdos comunitarios
}

Nicolasa María Durán Palacio; Magda Victoria Díaz Alzate²; Juan Carlos Tabares Castrillón³; Lyda Marcela Suárez Pulgarín ${ }^{4}$

Recibido: 02/06/2020; Revisado: 04/06/2020; Aceptado: 07/10/2020

Resumen. Este artículo presenta la experiencia de la asamblea comunitaria deliberativa en los procesos participativos de la Corporación para el Desarrollo Picacho con Futuro, para la toma de decisiones públicas en la resolución de problemas de la comunidad. A través de un diseño cualitativo narrativo con entrevistas en profundidad a líderes y lideresas de la Corporación, se identificó que, en la organización de base comunitaria, la configuración de espacios de participación para la deliberación promueve otros modos de poder y actuación colectiva para resolver problemas, que están más relacionados con la construcción de acuerdos para la transformación política del territorio, la reconstrucción de relaciones de confianza y solidaridad.

Palabras clave: comunidad urbana, asamblea, participación comunitaria, organización y gestión, desarrollo participativo.

\section{[en] Deliberative assemblies: a strategy for building community agreements}

Abstract. This article presents the experience of deliberative community assemblies in the participative processes of the Picacho con Futuro community development corporation, involving public decision-making to resolve community problems. A narrative qualitative design involving in-depth interviews with corporation leaders was used to identify that in the underlying community organization, the establishment of participative spaces for deliberation promotes other forms of power and collective action to resolve problems; these forms are more related to building agreements for the political transformation of the territory and reconstructing relationships of trust and solidarity.

Keywords: urban community; assembly; community participation; organisation and management; participative development

Sumario: Introducción. 1. Metodología. 2. Resultados. 2.1 La asamblea de deliberación y la construcción de acuerdos comunitarios. El caso de la Corporación para el Desarrollo Picacho con Futuro. 2.2 Asambleas de deliberación para resistir la exclusión social y las acciones violentas de actores armados en el territorio. 3. A modo de conclusiones. 4. Referencias bibliográficas.

Cómo citar: Durán Palacio, N. M.; Díaz Alzate, M. V.; Tabares Castrillón, J. C.; Suárez Pulgarín, L. M. (2021) La asamblea de deliberación: estrategia para la edificación de acuerdos comunitarios. Cuadernos de Trabajo Social, 34(2), 457-465.

\section{Introducción}

1 Universidad Católica Luis Amigó; Colombia.

E-mail: nicolasa.duranpa@amigo.edu.co

2 Universidad Católica Luis Amigó; Colombia.

E-mail: magda.diazal@amigo.edu.co

3 Corporación para el Desarrollo Picacho con Futuro; Colombia.

E-mail: juancperiodista@gmail.com

4 Corporación para el Desarrollo Picacho con Futuro; Colombia.

E-mail: 1marcelasuarezp@gmail.com 
La noción de organización comunitaria hace alusión a la manera cómo la gente en las comunidades se organiza para dar respuesta a sus problemas locales, teniendo como destinatarios a los integrantes de la propia comunidad en la que actúan. Sus acciones además de ser colectivas son polifacéticas y vinculantes, tienen un fuerte arraigo en el territorio y están sujetas a él (Rofman, 2009).

Cuando se estudian y describen las formas en que las comunidades, especialmente las más empobrecidas se disponen y organizan para asumir las tareas incumplidas por la institucionalidad del Estado, se hallan diferencias en cuanto al tipo de acciones que ejecutan y los objetivos hacia donde se orientan. No toda iniciativa de base comunitaria organizada, propicia ni edifica espacios participativos para la deliberación racional en la toma de decisiones comunitarias, ni realiza acciones de comunidad sobre sí y para sí misma. En este sentido, la deliberación es entendida como escenario dialógico de encuentro que convoca a los sujetos a considerar situaciones, hechos problemáticos de la vida en común, desde múltiples puntos de vista, conversando entre sí, discutiendo, cuestionando y pensando críticamente las opciones que tienen para actuar colectivamente, procurando el mayor bien común, ampliar sus perspectivas, opiniones y entendimientos (Cohen, 1989; Passerin, 2000; Parkinson, 2004; Eagan, 2016). Este aspecto es crucial en el compromiso y el empoderamiento comunitario, dado que la deliberación constituye un valor en sí misma para la democracia como ideal político, ya que patentiza el mérito de la cooperación social, más allá de los valores de la igualdad, equidad y respeto a las diferencias.

Sin embargo, para que la deliberación sea un procedimiento efectivo, significativo en y para las comunidades, se precisa empoderarlas expresamente, a través de la organización de base, la construcción de alianzas comunitarias y la formación para la cultura del diálogo. Los ejercicios reiterativos de la participación deliberativa, hacen única a la deliberación comunitaria en la redistribución y transformación del poder (Cohen, 1993; Habermas, 1999a, 1999b).

El acto mismo del compromiso de los sujetos en la deliberación comunitaria, los convierte en actores de los procesos de poder político, y a su comunidad en una organización de base comunitaria, con incidencia en otros escenarios de la sociedad civil, en los que se debaten cuestiones que interesan a la comunidad en conjunto, en los cuales es preciso intervenir como ciudadanos activos (Rofman, 2009).

La historia de la Corporación para el Desarrollo Picacho con Futuro, hacia los años ochenta, ubicada en la parte alta de la Comuna 6 de la ciudad de Medellín, está relacionada directamente con las reflexiones colectivas surgidas desde el deseo común de mejorar las condiciones de vida del territorio habitado; asunto que los llevó a establecer una estructura organizativa de base territorial, articulando las 16 organizaciones comunitarias, que adelantaban procesos sociales, conformadas por vecinos que habitan la misma comuna y que paulatinamente fueron encargándose del suministro de servicios sociales sin fines de lucro a su misma comunidad, allí en donde las instituciones del Estado y de la municipalidad no hacen presencia, desde los comienzos del asentamiento de la población en el territorio de la Comuna 6 y el barrio París del Municipio de Bello, Antioquia. La alianza entre organizaciones de base territorial, no solo favoreció el empoderamiento de la comunidad, sino que además propició el fortalecimiento de su tejido social. Esto se reflejó en su primer Plan Institucional, a principios de los años noventa, a partir del cual las organizaciones miembros, comenzaron a trabajar en modo articulado, como expresión de una comunidad que se resiste a la exclusión social.

Las acciones comunitarias de las organizaciones que constituyen la Corporación, se entretejen en el contexto de la exclusión social y el conflicto armado local en la ciudad de Medellín, de modo particular en la Comuna 6, en cuyo territorio los actores armados se disputan el control y el dominio de la población residente de los barrios incrustados en las laderas del Cerro Picacho; Mirador del Doce, El Triunfo, Progreso número 2, Picacho y Picachito en el Municipio de Medellín y el barrio París del Municipio de Bello. Desde la ocupación de los terrenos, la implantación, urbanización y constitución sociocultural de la Comuna 6 , los conflictos por el territorio, la vivienda, los espacios públicos, la seguridad, los suministros públicos y la provisión de derechos económicos, políticos y sociales, han estado presentes en la localidad. Se trata de un contexto marcado históricamente por la tensión entre las lógicas dominantes de las élites, la gubernamentalidad de la ciudad, la segregación y la exclusión social y las resistencias populares de 
las organizaciones comunitarias de la comuna, por ejercer y defender su derecho a un territorio decente, a poseer y disfrutar de bienes colectivos, a habitar y transitar libremente los espacios de ciudad y a ser reconocidos como actores protagónicos en la construcción de la misma (Nieto López, 2013) .

El proceso de poblamiento y construcción de la comuna 6 , del mismo modo que las otras comunas populares de Medellín, aunque con algunas dinámicas particulares en ellas, ha sido un proceso paradójico de disputas, resistencias, transversalizado por relaciones de poder entre la planeación urbana del municipio, la influencia del señorío económico privado de las élites de la ciudad, la apropiación del uso de los espacios por parte de actores ilegales violentos y las tenaces acciones comunitarias de resistencias no violentas de recuperación y apropiación de sus escenarios barriales. Estas acciones de autoconstrucción y autogestión del territorio, caracterizan a las organizaciones de base comunitaria que integran la Corporación para el Desarrollo Picacho con Futuro, quienes, en su afán de tener un espacio digno en la ciudad, emprendieron la construcción de obras de abastecimiento colectivo, cimentación de viviendas, calles, andenes, escaleras, desagües, entamboramientos de quebradas, edificación de la sede comunal. Estos procesos de autogestión comunitaria, además de evidenciar la ausencia del Estado, le reclaman su obligación de garantías de derechos económicos y sociales para los pobladores del territorio.

Por otro lado, las acciones organizadas de la comunidad para la cooperación y ayuda mutua entre sus habitantes, les ha permitido desarrollar un sentido de identidad socio-cultural y de arraigo con el territorio y un sentido de pertenencia a un nosotros (Nieto López, 2013). En este sentido, actuando colectivamente, construyen acciones organizadas en términos relacionales, cognoscitivos y afectivos que le dan sentido al "habitar juntos" y a los fines comunes que persiguen. Las acciones comunitarias organizadas, surgen de espacios públicos de reunión de los miembros de la comunidad y de sus organizaciones comunitarias, convocada por los líderes y lideresas, para deliberar sobre cuestiones de interés común, tomar decisiones vinculantes para actuar concertadamente. En este texto se exponen los modos en que las asambleas comunitarias de deliberación en la Corporación para el Desarrollo Picacho con Futuro, promueven la organización comunita- ria en la gestión política y social de la transformación del territorio y fortalece los vínculos de cooperación, solidaridad y trabajo articulado entre las organizaciones de base de su territorio, a partir del reconocimiento entre ellas y la definición de acciones colectivas.

A través de la investigación de la acción comunitaria, organizada para la solución de problemas locales, la Corporación para el desarrollo Picacho con Futuro se configuró en la unidad de análisis del trabajo de indagación, buscando comprender cómo las asambleas comunitarias de deliberación, han potenciado las acciones de las organizaciones, en la autogestión de sus necesidades y problemas particulares.

La manera en que Picacho con Futuro, ha logrado sostenerse como asociación por más de tres décadas en el territorio, manteniendo sus apuestas de comunidad, constituye el eje de reflexión derivada de una investigación participativa, con diseño cualitativo narrativo, que involucró a los líderes y lideresas de Picacho con Futuro actuando en sus comunidades, narrando los modos de autocomprensión comunitaria de sus problemas, los programas y proyectos de gestión participativa, en los que las asambleas de deliberación, han sido el espacio en el que emergen concertaciones con actores comunitarios, agentes públicos y privados, en el establecimiento de alianzas que se cristalizan en proyectos de intervención social en el territorio, además del fortalecimiento de las organizaciones sociales.

Los resultados emergentes del repertorio narrativo de esta investigación se presentarán en dos categorías analíticas: 1. La asamblea comunitaria de deliberación y 2 . Tensiones y resistencias comunitarias frente a la intervención estatal.

\section{Metodología}

La investigación de acción comunitaria, se fundamenta en la tradición de la teoría socio-crítica, en su interés cognoscitivo (Habermas, 2012) de construir teoría basada en la comunidad, a partir de cómo esta interpreta y actúa para resolver sus necesidades y problemas locales. Este tipo de proceso investigativo, supone la alianza entre las organizaciones comunitarias con investigadores que realizan estudios de campo, con un interés colaborativo para la transformación de las comunidades 
en territorios de vulnerabilidad, precariedad, inequidades sociales duraderas y abandono estatal. La investigación de acción comunitaria se orienta según los siguientes principios compartidos: Los miembros de la comunidad son actores colaboradores de la investigación (Israel, Eng, Schulz y Parker, 2005). Las intervenciones de las lideresas y los líderes comunitarios, contienen las construcciones sociales y culturales de la comunidad (Reason y Bradbury, 2001). La asociación de investigación con la comunidad requiere formas de investigación más democráticas y deliberativas, de tal forma que se puedan representar diversos intereses públicos y experiencias comunitarias (Jocz y Quelch, 2008; Ozanne, Corus y Saatcioglu, 2009). Las personas tienen una mayor agencia cuando desarrollan nuevas habilidades y exploran experiencias sin utilizar en el proceso de investigación, por eso la participación también es un fin en sí misma en la investigación de acción comunitaria (Ger 1997; Talukdar, Gulyani y Salmen 2005).

En esta investigación se tomó como unidad de análisis a la Corporación para el Desarrollo Picacho con Futuro. Organización comunitaria, constituida formalmente en febrero de 1994 por un conjunto de organizaciones de base (asociación de madres comunitarias, junta de acción comunal, barrios unidos, club deportivo senderos de paz, colectivo juvenil audiovisual panorámicas), como expresión de un proyecto social y político de una comunidad que se resiste a la exclusión y marginación de la vida de la ciudad de Medellín, Colombia. La corporación, emergió en un contexto de múltiples pobrezas y el agravamiento del conflicto armado entre bandas y milicias en el territorio y en otros sectores periféricos de Medellín. Este contexto marcará su trayectoria de acción y de dinámica movilizadora de sus comunidades, a través de la participación y la deliberación pública.

En su territorio, Picacho con Futuro ha liderado, desde su fundación, experiencias articuladas de múltiples resistencias frente a las pobrezas, la exclusión social y el dominio violento de sus comunidades, por parte de acto- res ilegales armados. Estas experiencias, han logrado insertar a la Corporación en espacios y dinámicas de ciudad, a la vez que sus organizaciones comunitarias han logrado vincularse y participar en escenarios y procesos de la municipalidad: deliberación sobre la asignación del presupuesto participativo ${ }^{5}$, de los recursos públicos para su comuna e intervención en los planes de desarrollo local ${ }^{6}$.

Por otro lado, esta corporación, ha tejido relaciones de trabajo colaborativo con instituciones gubernamentales como la Personería municipal, la Defensoría del Pueblo ${ }^{7}$, universidades públicas y privadas de la ciudad. Actualmente, Picacho con Futuro, ajusta sus objetivos y metas de acuerdo a sus lecturas comunitarias y ciudadanas, sostiene sus apuestas de pensamiento, reflexiones compartidas y decisiones concertadas para la generación de un buen vivir en su territorio.

Los participantes directos, en esta investigación, fueron cuatro (4) personas que lideran procesos de fortalecimiento y compromisos comunitarios en la Organización, cuyo trabajo gira alrededor de cuatro líneas de trabajo:

1. Promoción y fortalecimiento de la organización comunitaria, mediante el acompañamiento, formación y asesoría a las organizaciones comunitaria.

2. Incidencia política, reconociendo que el conflicto es propio de la diversidad, este acompañamiento se orienta hacia la construcción de acuerdos con la municipalidad (políticas públicas, planes municipales, $\mathrm{y}$ proyectos sociales), en escenarios colectivos del territorio (mesas de trabajo, alianzas estratégicas) que garanticen efectivamente la participación ciudadana-comunitaria en los espacios de toma de decisiones que afectan sus vidas.

3. El fortalecimiento institucional, a través de la implementación de estrategias de sostenibilidad creativas, innovadoras y pertinentes, que surgen del intercambio de saberes entre las organizaciones miembro y las prácticas de labor comunitaria.

4. La articulación de las tres líneas anteriores,

El presupuesto participativo es un proceso de consulta y diálogo deliberativo; entre las comunidades y las autoridades municipales; sobre las prioridades de inversión de los recursos públicos en el municipio de Medellín; dividido en comunas.

6 Son instrumentos de planeación participativa local; construidos a partir de acuerdos entre los habitantes de un territorio; para orientar concertadamente; el desarrollo de una comuna. Estos planes locales se articulan con el Plan de Desarrollo Municipal de Medellín.

En Colombia; las personerías municipales y la Defensoría del Pueblo hacen parte de lo que se denomina el Ministerio público; y se constituyen en las entidades rectoras de la defensa; promoción; protección; divulgación y ejercicio de los derechos humanos. 
a partir de una estrategia de comunicación que construye contenidos comunicativos propios (boletines, videos, manuales, publicaciones conjuntas entre colectivos y academia, emisora comunitaria virtual), para ayudar al empoderamiento ciudadano y su participación activa en el devenir de su comunidad (Corporación para el Desarro1lo Picacho con Futuro, s.f.). El fundamento para el despliegue de estas líneas de trabajo, está en el dinamismo de las asambleas comunitarias.

Los relatos narrativos de las lideresas y líderes comunitarios sobre la experiencia de las asambleas comunitarias de deliberación, luego de ser transcritos, se analizaron siguiendo la lógica de la construcción de la teoría fundamentada de Glaser \& Strauss, 1967), teniendo como procedimiento analítico central, la comparación constante de los datos contenidos en las narraciones, en dos niveles: descriptivo y relacional. En el primero, la descripción se realizó mediante la codificación de las narrativas, luego, en el nivel relacional, la integración de códigos en categorías abarcadoras, permitió pensar los datos, organizarlos relacionalmente, conceptualizarlos y sintetizarlos. Todo ello posibilitó la emergencia progresiva de conjeturas teóricas, en estrecha relación con los relatos. Este proceso analítico derivó en la identificación de cuatro pilares básicos (la asamblea de deliberación, condiciones, acciones comunitarias y consecuencias), para la explicación central del objetivo de la investigación: describir (comprender) los modos en que las asambleas de deliberación, permiten la edificación de acuerdos comunitarios. En este texto se presentan las relaciones que se establecieron entre estos cuatro pilares emergentes del proceso sistemático de análisis inductivo.

\section{Resultados}

En este apartado se presentan dos categorías que emergen del proceso analítico de las narrativas logradas a partir de las entrevistas realizadas durante el proceso investigativo. $\mathrm{La}$ asamblea de la deliberación como una estrategia alternativa a la democracia representativa que ha sido la herramienta de participación más conocida, atraviesa lo hallado y se constituye en una novedad de organización comu- nitaria, en tanto ubica el reconocimiento de la pluralidad humana como principio para la construcción de acuerdos y sentidos comunes, lo que indica que la participación comunitaria para la toma de decisiones no se circunscribe exclusivamente en los modos de liderazgos representativos, sino que puede contener múltiples voces comunes que también han construido el sentido de comunidad.

\subsection{La asamblea de deliberación y la cons- trucción de acuerdos comunitarios. El caso de la Corporación para el Desarrollo Pica- cho con Futuro}

La asamblea de deliberación se configura a sí misma como un espacio relacional de la comunidad, para la reflexión, el debate y la resolución de asuntos que definen y afectan tanto la vida personal, como la vida en común. Al reunirse, las personas buscan practicar el poder a través de la gobernanza participativa y construir planes de acción colectivos para el cambio sistémico. Por su íntima conexión con el modelo de democracia deliberativa (Rawls, 1988; 2001; Cohen, 1989, 1993; Elster, 1997; 2008; Habermas 1999a;199b), la asamblea exige la superación de individualismos centrados en intereses y preferencias personales, en procura de una mayor preocupación por el bien común. Para ello, recurre al diálogo y a la argumentación como elementos centrales del método deliberativo para la toma de decisiones colectivas.

La participación de la comunidad, en el contexto de la Corporación para el Desarrollo Picacho con Futuro, va mucho más allá de la información sobre asuntos de interés colectivo y la obtención del consentimiento comunitario, a través de la tradicional consulta por votación. Las asambleas en esta localidad representan la esencia de las organizaciones comunitarias afiliadas a la Corporación y la síntesis de sus conocimientos y compromisos sociales. Así mismo, reivindican el papel de la implicación de la población en la configuración y fortalecimiento de la vida comunitaria, desde la pluralidad que la caracterizó desde los orígenes de su fundación. Los sujetos de la comunidad se reúnen no para pensarse desde la búsqueda ansiosa de lo común, sino desde la posibilidad de construir convivencias a partir del doble reconocimiento de su diversidad y su semejanza. En esta afirmación, radica el carácter singular de los espacios de las asambleas de delibera- 
ción: juntarse para pensar con otros distintos y semejantes. Porque justo lo que más devela la deliberación en una asamblea, es que lo común a todos es la diferencia. Esta es la paradoja de la condición humana: distintos entre iguales (Arendt, 2005).

Aqui pensar diferente y optar por lo distinto, no es un problema. La riqueza está en que somos diferentes, pero nos ponemos de acuerdo en lo colectivo. Y eso es para nosotros lo político, ahí está: ponernos de acuerdo sobre cuál es el desarrollo que queremos para esta comunidad (Entrevista a líder 1, 2018).

Cuando las organizaciones comunitarias de la Corporación se reúnen en asamblea de deliberación, estas funcionan basadas en tres principios: 1) todas las personas son pensadoras; 2) poseen saberes que pueden aportar a la solución de los problemas locales; y 3) la juntanza para la acción es más poderosa que la actuación por separado. Sus asambleas representan el poder y las capacidades de sus organizaciones que aporta al movimiento social de la ciudad de Medellín. Estas asambleas no representan a ninguna coalición ni alianza política, tampoco a ideología alguna. Se trata de un espacio compartido para conocerse mejor, identificar sus diferencias, crear conciencia frente a las problemáticas locales y de ciudad, tejer relaciones más fuertes entre las personas y las organizaciones de la comunidad, generándose responsabilidades mutuas para el trabajo colectivo.

La corporación ha tenido una reflexión histórica sobre cómo nosotros entendemos la politica, y la concebimos como esa posibilidad de ponernos de acuerdo para fines colectivos, para lo público, para lo común. Entonces hemos pasado por muchas discusiones en las asambleas. Pero como el desarrollo de la comunidad es un asunto público, y eso es una responsabilidad de todos, entonces una acción colectiva, es una acción política. Logramos desde un principio diferenciar lo político de lo electoral (Entrevista a líder 1, 2018).

En su proceder, estas asambleas se orientan desde los métodos de la pedagogía popular (Freire, 1961; 1963; 1967; 1970), para la facilitación del pensamiento crítico colectivo que deviene en acción coordinada, que representa la suma de las ideas y compromisos comunitarios. Cuando la asamblea comunita- ria se reúne, delibera sobre tres interrogantes fundamentales: ¿cuál es (son) el(los) problema(s)? ¿cuáles son las soluciones posibles? y ¿qué podemos hacer al respecto? En ella se da cabida a todas las voces de manera circular e involucra el pensamiento, las visiones de todos los participantes para sintetizar y acordar colectivamente las acciones a seguir. El resultado de las asambleas en forma de acciones colectivas coordinadas, crean y fortalecen la gobernanza comunitaria, aumentan la cohesión entre las organizaciones de la Corporación, ayudan a la convergencia de poderes para la representación de la Comuna 6 Doce de octubre, ante la institucionalidad del gobierno municipal y ante otras organizaciones sociales en la ciudad.

Concretamente, de las experiencias de participación en sus asambleas comunitarias de deliberación, han surgido acciones como la intervención en los procesos de planeación participativa para el desarrollo local de la Comuna 6, desde el año 1994 y los actos de resistencia no violenta para enfrentar a los actores armados en el territorio.

\subsection{Asambleas de deliberación para resistir la exclusión social y las acciones violentas de actores armados en el territorio}

El derrotero de las acciones conjuntas y colectivas de la Corporación para el Desarrollo Picacho con Futuro, enlaza con un pasado de luchas y resistencias, frente a la pobreza y la exclusión social, y con un presente de resistencias no violentas para contrapesar las persistentes violencias provenientes de los actores armados ilegales ejerciendo su poder y control en el territorio, que han cargado al sector con el estigma de la segregación. Muy prontamente, las dinámicas de trabajo comunitario de las organizaciones ligadas a Picacho con Futuro, se vieron abocadas al desafío de articular su compromiso comunitario con la defensa de la comunidad asediada por la violencia de grupos armados, ya que, sin condiciones políticas mínimas de convivencia, que aseguraran el respeto a la vida, a la libertad personal de los líderes, lideresas y miembros de la comunidad, ningún tipo de trabajo comunitario es posible (Nieto López, 2013).

El cultivo de las asambleas como espacios relacionales de deliberación, han suscitado experiencias de transformación política en el territorio de la comunidad. Un ejemplo de ello, 
data de los años noventa, época en la que las organizaciones asumieron colectivamente la iniciativa de buscar interlocución con los jefes de los grupos armados enfrentados por el control de la zona, para mediar entre ellos el establecimiento de pactos de no agresión, necesarios para el proceso de mejoramiento de las condiciones de vida de su comunidad, el respeto a los derechos fundamentales de sus habitantes: a la vida, a la movilidad segura y tranquila, además de vivir en paz.

Yo creo que una de las cosas que han marcado políticamente la transformación del territorio es el tema de la interlocución con grupos armados. Eso nos ha marcado durante treinta años de experiencia con las milicias populares, con la banda de Frank, con los paramilitares, $y$ hoy con esas nuevas bandas que quedaron en el territorio. Yo le atribuyo mucho a un tipo de acciones resultado de las asambleas comunitarias, que de manera colectiva abordamos el tema de la violencia en el sector por parte de los grupos armados, se discutió qué hacer, y se propuso que esto lo afrontáramos colectivamente, entonces en los años 90 en una asamblea comunitaria dijimos: hay que hablar con esos grupos y decirles que dejen de enfrentarse; más bien sentémonos y miremos qué vamos a hacer, porque esta situación no va a posibilitar trabajar con la comunidad (Entrevista a líder 1, 2018).

Un emergente significativo de la interlocución de las organizaciones comunitarias, ligadas a Picacho con Futuro, fue la firma del pacto de no agresión, derivado de la negociación dialogada del conflicto entre grupos armados, representantes de la comunidad y la Administración municipal de Medellín (Nieto López, 2013).

A partir de las mejoras de las condiciones sociopolíticas, derivadas del pacto de no agresión entre actores armados en el territorio, Picacho con Futuro y sus organizaciones comunitarias han mantenido un liderazgo importante en los procesos de gestión participativa del desarrollo local. Sus experiencias de asambleas de deliberación para el trabajo comunitario, le otorgaron empoderamiento en los diálogos públicos para la planeación del desarrollo local.

Cada 15 días estamos reuniéndonos, particularmente tomamos la decisión de este año de proponer un encuentro quincenal con las orga- nizaciones, en vista de que varias situaciones, en particular, en las que el equipo de la corporación, veníamos participando en un conjunto de escenarios y discusiones en la ciudad, pero considerábamos que muchas de esas decisiones no estaban pasando por las bases de las organizaciones. Entonces dijimos abramos un espacio donde empecemos a abordar esto: los espacios y reflexiones de ciudad y pongamos en discusión esos temas con los actores de la comunidad (Entrevista, a líder, 2018).

Estos diálogos se enmarcaron en el contexto de la reformulación de lo que se considera como público, de la reivindicación del derecho a la ciudad y de la redefinición del territorio como construcción colectiva, más allá de su ordenación físico espacial, funcional (Obando y Gómez, 2003). Por otro lado, los líderes y lideresas de las organizaciones comunitarias conciben la construcción de los planes de desarrollo local, a partir de la discusión entre actores comunitarios y de la negociación con otros estamentos sociales y políticos de la ciudad. De lo contrario, estos planes no pueden ser posicionados como compromiso en los territorios.

No se trata de que la gente sepa que existe un plan estratégico de desarrollo local, sino que participen en su construcción, lo sientan como algo propio, lo entiendan, conozcan en qué consiste, para qué tener un plan y cuál es la intención de tenerlo (Entrevista a líder, 2018).

La experiencia participativa de la Corporación y sus organizaciones filiales en la planificación del desarrollo local, no sólo amplió el alcance de sus asambleas comunitarias hacia lo más público con la administración municipal, sino que además confrontó sus relaciones con su propia comunidad y con lo estatal. Hasta dónde el Estado que convoca a la organización comunitaria para la planeación participativa, actúa como garante de los derechos de los ciudadanos y qué tanto las necesidades de la comunidad son resueltas o no, de manera incluyente con su intervención en la planeación. Esto señala una diferencia significativa entre la participación de las organizaciones en la planificación del desarrollo local y las asambleas comunitarias de deliberación. Mientras la planeación opera dentro de las estructuras básicas de la democracia participativa, subordinando la deliberación que pueda darse en 
ella al proceso de la planificación, la deliberación que acontece en las asambleas comunitarias subraya la importancia de la organización de la comunidad y de su participación como resultado de la deliberación, basada en la idea de la democracia deliberativa, en la que la comunidad y sus habitantes son un otro distinto, plural, con el que el Estado, representado en la municipalidad, debe debatir el interés por lo público.

\section{A modo de conclusiones}

Las asambleas de deliberación comunitaria reivindican el papel político de la discusión como método para la toma de decisiones y la acción colectiva. En tanto las decisiones políticas atañen a todos e implican relaciones de poder y distribución de recursos públicos, entonces la participación de las comunidades en tales decisiones, sirve para el control de los poderes y orientan sus reclamos de justicia social.

Aunque los saberes surgidos de las cotidianidades de las asambleas comunitarias de deliberación, inciden en la apropiación del territorio y en el establecimiento de relaciones interinstitucionales, surge el interrogante de saber si, en sí mismos, los acuerdos de las deliberaciones en estas asambleas, alcanzan a incidir efectivamente en los espacios de gobierno, especialmente en la toma de decisiones que obligan a las administraciones municipales a cumplir los compromisos de inversión social en la Comuna 6. De igual modo, también emerge la inquietud: de qué tanto los sujetos participantes en las asambleas comunitarias, se empoderan efectivamente, a través del ejercicio de la deliberación.

Por otra parte, aunque el objetivo de los procesos participativos en la planeación local es la potenciación de los sujetos como actores activos en los procesos de planificación, acontece una relación paradojal entre la exigencia de un pronto consenso en la planeación participativa para el cumplimiento de los planes de gobierno y el proceso formativo de la deliberación en el que los sujetos más reticentes al compromiso se transformen en actores deliberantes con una mayor implicación en la vida de su comunidad.

\section{Referencias bibliográficas}

Cohen, J. (1993). Moral Pluralism and Political Consensus. En: D. Coop, J. Hampton y J.E. Roemrr (eds.), The Idea of Democracy. Cambridge: University Press, Cambridge.

Cohen, J. (1989). Deliberation and Democratic Legitimacy. En: A. Hamlin y P. Philip (eds.), The good polity: normative analysis of the state. Nueva York: Blackwell.

Corporación Picacho con Futuro. (s.f). Picacho con Futuro. Recuperado de: https://www.picachoconfuturo. org/index.php

Eagan, J. (2016). Deliberative democracy. Encyclopcedia Britannica. Gran Bretaña: Encyclopædia Britannica, inc. Recuperado de: https://www.britannica.com/topic/deliberative-democracy

Elster, J. (1997). El cemento de la sociedad: las paradojas del orden social. Barcelona: Gedisa

Elster, J. (2018). Constitucionalismo y democracia. México: Fondo de Cultura Económica.

Freire, P. (1961). El propósito de una administración. Recife: University Press.

Freire, P. (1963). La alfabetización y la conciencia. Porto Alegre: Editora Emma.

Freire, P. (1967). La educación como práctica de la libertad. Introducción Francis C. Weffort. Río de Janeiro: Paz e Terra.

Freire, P. (1970). Pedagogía del oprimido. Nueva York: Herder y Herder.

Ger, G. (1997). Human Development and Humane Consumption: Well-Being Beyond the Good Life. Journal of public policy \& marketing, (16), 110-125.

Glaser, B.G. y Strauss, A.L. (1967). The discovery of grounded theory: strategies for qualitative research. New Brunswick: Aldine Transaction. Recuperado de: http://www.sxf.uevora.pt/wp-content/ uploads/2013/03/Glaser_1967.pdf

Habermas, J. (1999a). La inclusión del otro. Barcelona: Paidós.

Habermas, J. (1999b). Teoría de la acción comunicativa. Madrid: Taurus.

Habermas, J. (2012). Teoría y praxis. Estudios de filosofía social. Madrid: Tecnos 
Israel, B.A., Eng, E., Schulz, A.J. y Parker, E.A. (2005), Methods in community-based participatory research for health. San Francisco: Jossey-Bass. Recuperado de: https://media.wiley.com/product_data/ excerpt/6X/11180218/111802186X-145.pdf

Jocz, K.E. y Quelch, J.A. (2008). An Exploration of Marketing's Impacts on Society: A Perspective Linked to Democracy. Journal of Public Policy \& Marketing, 27(2), 202-206. Doi: https://doi.org/10.1509/ jppm.27.2.202

Mouffe, Ch. (2003). La paradoja democrática. Barcelona: Gedisa.

Nieto López, J.R. (2013). Resistencia civil no armada. La voz y la fuga de las comunidades urbanas. Medellín: Hombre Nuevo Editores.

Obando A. y Gómez E. (2003). La planeación participativa una apuesta de ciudad. Medellín, Colombia: Corporaciones Región, CEDECIS, Con-vivamos, IPC y Fundación Social.

Ozanne, J. L., Corus, C. y Saatcioglu, B. (2009). The Philosophy and Methods of Deliberative Democracy: Implications for Public Policy and Marketing. Journal of Public Policy \& Marketing, 28(1), 29-40. Doi: https://doi.org/10.1509/jppm.28.1.29

Parkinson, J. (2004). Why Deliberate? The encounter between deliberation and new public managers. Journal Public Adminstration. 82(2), 377-395. Doi: https://doi.org/10.1111/j.0033-3298.2004.00399.x

Passerin d'Entreves, M. (2000). Legitimacy and Democratic Deliberation. Theoria, 47. 14-26. Doi: https:// doi.org/10.3167/004058100782485666.

Rawls, J. (1988). Libertad, igualdad y derecho: las conferencias Tanner sobre filosofía moral. Barcelona: Ariel.

Rawls, J. (2001). El derecho de gentes y una revisión de la idea de razón pública. Barcelona: Paidós

Reason, P. y Bradbury, H. (2001). Introduction: Inquiry and Participation in Search of a World Worthy of Human Aspiration. En: P. Reason y H. Bradbury (eds.), Handbook of Action Research (pp. 1-14). Thousand Oaks, CA: Sage Publications. Recuperado de: https://pdfs.semanticscholar.org/ecd1/0fb37dfc576208c5497e2613968bcdb70e22.pdf

Rofman, A. (2009). Organizaciones de la sociedad civil y políticas sociales en el área metropolitana de Buenos Aires: entre las teorías y las realidades. Revista Española del Tercer Sector, (12), 157-181.

Talukdar, D., Gulyani, S. y Salmen, L.F. (2005). Customer Orientation in the Context of Development Projects: Insights from the World Bank. Journal of Public Policy \& Marketing, 24(1), 100-111. Doi: https://doi.org/10.1509/jppm.24.1.100.63894 